\title{
Iridium-Catalyzed Asymmetric \\ Dearomatization of Pyridines and Pyrazines
}

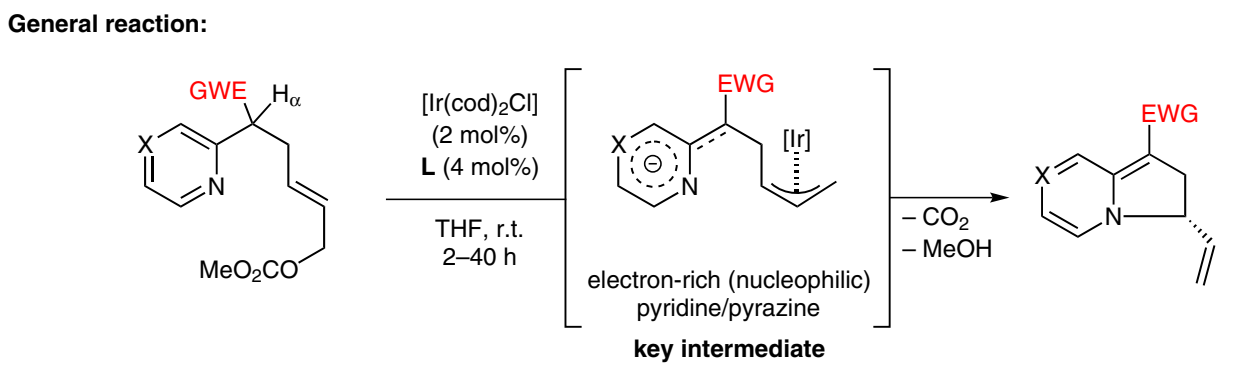

\section{Key words}

pyridines

pyrazines

dearomatization

iridium

asymmetric

catalysis

SYNFACTwh
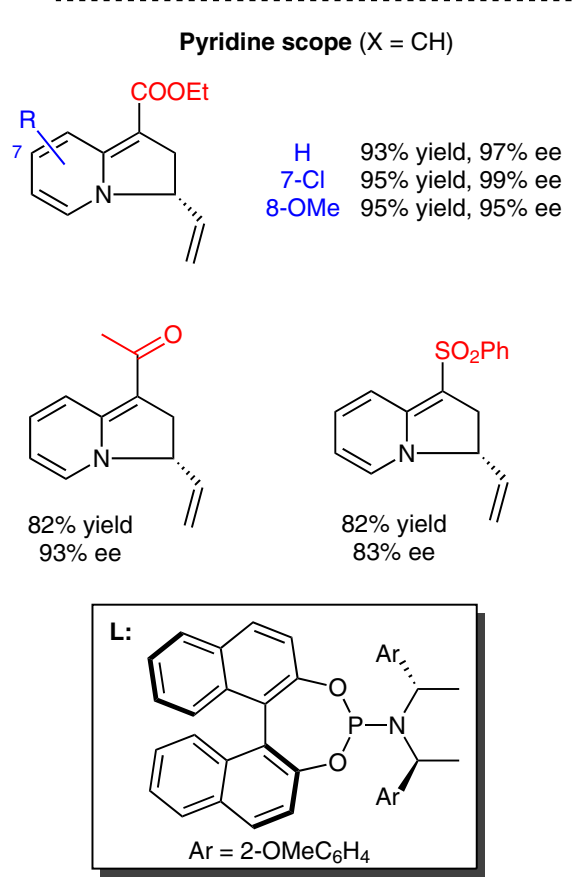

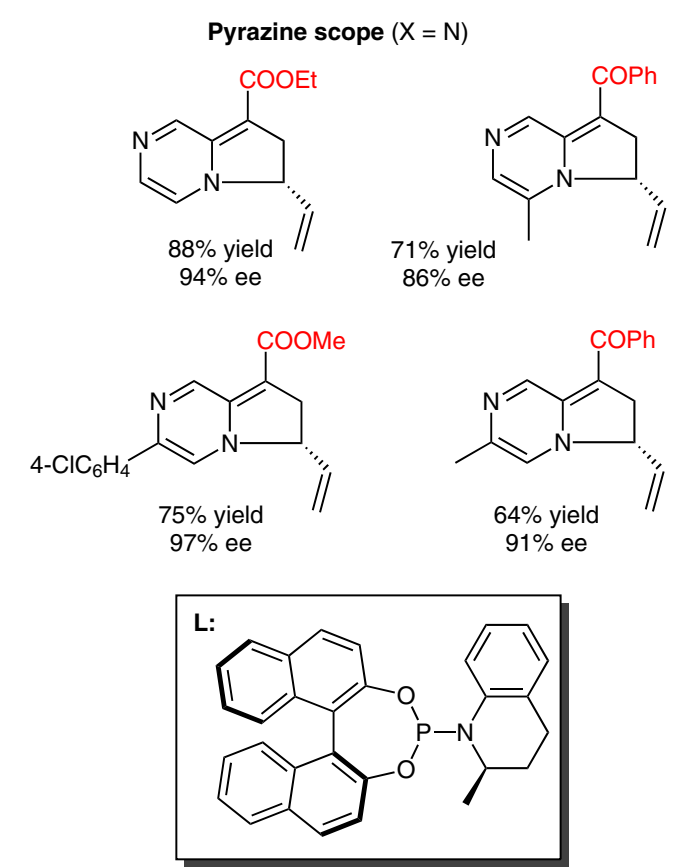

Significance: The authors report an Ir-catalyzed enantioselective allylic dearomatization of pyridines and pyrazines. The respective products are obtained in high yields (up to 99\%) and with excellent enantioselectivity (up to 99\% ee) under very mild reaction conditions. Due to the prevalence of pyridine and pyrazine motifs within biologically active compounds, the derived products could potentially serve as useful intermediates for targetoriented synthesis.
Comment: The presence of an electron-withdrawing group (EWG) acidifies the $\alpha$-position, enabling a deprotonation which provides electron density to the heteroaromatic ring. The increased electron density of the heterocycle enables the direct nucleophilic attack of the pendant Ir-allyl species.

SYNFACTS Contributors: Mark Lautens, Steffen Kress Dol: 10.1055/s-0034-1378409; Reg-No.: L08514SF 